\title{
CRUDE OIL DEGRADATION BY FILAMENTOUS FUNGI
}

\author{
JEROME J. PERRY AND C.E. CERNIGLIA \\ Department of Microbiology, North Carolina State University, \\ Raleigh, North Carolina 27607, U.S.A.
}

(Received October 25, 1972)

The common occurrence of tar lumps in littoral areas, floating on the open ocean and inland seas, has been well documented $(1,2)$. These oil pollutants are an immediate hazard to water fowl and other marine life (3, 4 ). Persistent tars might also be oxidized to substances that are a peril to food chains in the sea. It is inevitable with the increased off-shore drilling and shipping of oil that accidents occur and mandatory that these pollutants be removed from the environment as quickly and safely as possible. The natural pathway for pollutant mineralization is through microbial action. More efficient biodegradation of oil in the environment might be accomplished by increasing the number of pollutant-utilizing microbes and/or altering the environment to favor the growth of hydrocarbon-degrading microbes present in the biosphere.

We have been investigating the microbes in marine areas that utilize hydrocarbons as a source of carbon and energy. During these studies we isolated several fungi by enrichment culture that grew extensively on crude oils. Three of these isolates, identified as Cunninghamella elegans, Aspergillus versicolor, and a Eupenicillium sp., grew readily on paraffin-base crude oil resulting in a virtually complete disappearance of the oil within 7 days at $26^{\circ}$.

Enrichment for crude oil-degrading microbes was carried out by placing marine mud in a $12.5 \times 6.5 \mathrm{~cm}$ crystallization dish to a depth of 1.5 to $2 \mathrm{~cm}$ and adding $5 \mathrm{ml}$ of crude oil to the surface. Sea water was added periodically to prevent drying. After incubation at $26^{\circ}$ for $3-4$ weeks samples were taken from the oil/soil interface and streaked on the surface of agar in Felsen (quadrant) petri dishes. The petri dishes were prepared with sea water agar $(2.0 \%)$ supplemented with phosphate and nitrate to the level previously described (5). The sea water agar and minerals were sterilized separately. 

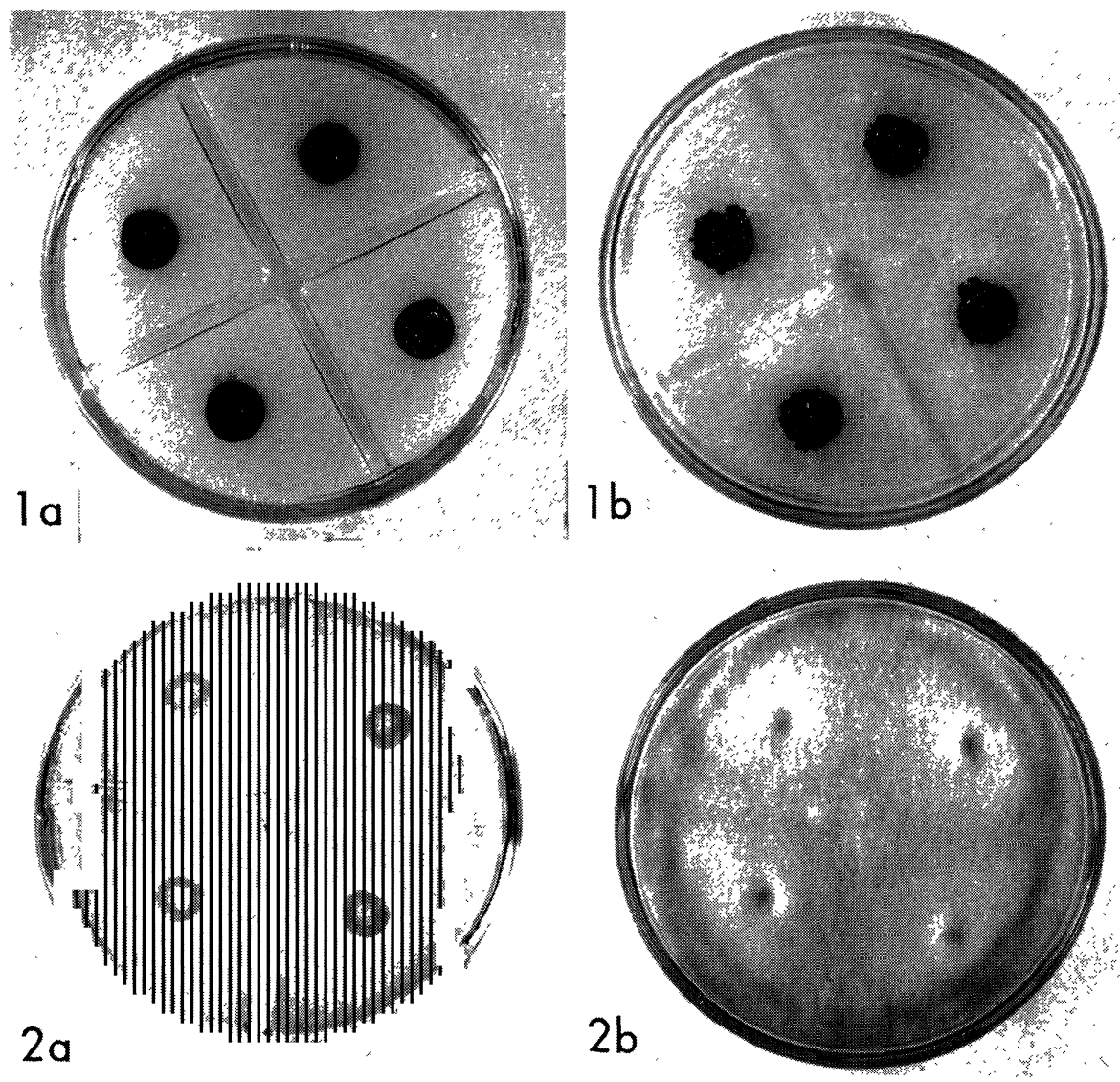

Figs. 1, 2. Growth of Cunninghamella elegans on crude oil.

Each plate contained $30 \mathrm{ml}$ of a sea water-salt agar medium. Wells were cut into the solidified agar with a cork borer and $0.4 \mathrm{ml}$ of crude oil was placed in the well. Inoculation was accomplished by streaking the plate with fungal mycelium. Incubation was for 7 days at $26^{\circ}$. Little growth occurred on asphalt-base crude oil (1a. bottom, 1b. top view). Extensive fungal growth is evident with paraffin-base crude oil (2a. bottom, 2b. top view).

Selected oils were added to the dishes by filling $1.5 \mathrm{~cm}$ wells cut into each quadrant of the dish. Bacterial and fungal growth was evident on most of the plates after 7-10 days of incubation. Visual observation suggested that crude oil was degraded more effectively by the fungi present than by the bacteria and several fungi were isolated in pure culture for further experimentation.

The ability of these fungal isolates to grow on hydrocarbons and crude oils was determined. The growth of one isolate, C. elegans, on asphalt and 
paraffin base crude oil is illustrated in Fig. 1. Both plates were inoculated with fungal mycelium and incubated at $26^{\circ}$ for 7 days. Sparse growth was observed on the plate containing asphalt base crude oil ( $1 \mathrm{a}$. bottom view, $1 \mathrm{~b}$. top view). This was in contrast with the significant growth demonstrated on paraffin-base crude oil ( $2 \mathrm{a}$. bottom view, $2 \mathrm{~b}$. top view). Abundant growth was evident on the agar surface and mycelium grew down into the well resulting in a complete utilization of the crude oil. The fungal isolates grew equally well on a mineral salt medium (5) and in sea water supplemented with a source of nitrogen and phosphate.

The relative amount of various crude oils utilized by fungi during growth was estimated by determining the amount of oil remaining in the culture medium after growth of the fungi. The undegraded oil was recovered and subjected to dry weight analysis. The amount of crude oil remaining was determined by extracting the mold mat and growth medium $(3 x)$ with chloroform (vol. equal to vol. of growth medium). The chloroform extract was placed in a tared beaker, the solvent removed by evaporation, and the dry weight of oil remaining determined. Control experiments demonstrated that crude oil can be quantitatively recovered in this manner. There was some loss of volatile material during evaporation. Presumably this volatile material would be utilized by the fungi or would be lost from oil spilled in the environment by evaporation. The results suggest that, after 7 days of growth, C. elegans had metabolized and incorporated into cells or converted to water-soluble material $90 \%$ of a paraffin-base crude oil and $40-45 \%$ of a heavy base crude. Mixed base crude oils fall between these extremes.

These experimental results suggest that microbes are present in the environment that can readily degrade paraffin-base crude oil. There is an insufficient amout of nitrogen and phosphate in the marine environment for the biodegradation of significant amounts of hydrocarbon pollutant and some supplementation of these elements would be necessary ( 6$)$. Further laboratory and field studies with these and other isolates are in progress.

Support was provided by the U. S. National Science Foundation Grant GB-23815 and Grant 416 from the North Carolina Board of Science and Technology. We thank Mrs. B. Hogarth for laboratory assistance.

\section{REFERENCES}

1) M.H. Horne, J.M. Teal, and R.H. Backus, Science, 168, 245 (1970).

2) B.F. MORRIS, Science, 173, 430 (1971).

3) N.A. Holme, In Oil on the Sea, ed. by D.P. Hoult, Plenum Press, New York, (1969) p. 1.

4) J.D. Carthy and D.R. Arthur, (ed.), The Biological Effects of Oil Pollution on Littoral Communities, Field Studies Council, London (1968).

5) E.R. Leadbetter and J.W. Foster, Arch. Mikrobiol., 30, 91 (1958).

6) W. Gunkel, Helgoländer Wiss. Meeresuntersuch., 15, 210 (1967). 